\title{
VIOLÊNCIA, RESSENTIMENTO E COMPREENSÃO NAS MEMÓRIAS DE GRACILIANO RAMOS
}

Gustavo Silveira Ribeiro

Pós-Lit/FALE/UFMG

\begin{abstract}
RESUMO
Este trabalho apresenta uma interpretação de Infância, de Graciliano Ramos, tendo como centro o debate ético que atravessa a obra. Considerado pessimista pela crítica, o texto foi lido quase sempre a partir das mesmas questões: violência, medo, ressentimento. Realizando movimento contrário, procurei expor a tese de que predomina no livro uma visão menos negativa do homem e do mundo.
\end{abstract}

\section{PALAVRAS-CHAVE}

Autobiografia, ressentimento, ética

Escrever sobre o passado é ação enganosa. Levado pelo desejo de evocar fatos antigos, o memorialista, na maioria dos casos, pensa estar apenas registrando o que ficou para trás. A memória, porém, tem suas leis próprias. Em meio às recordações daquele que lembra, invariavelmente, ela infiltra fragmentos de experiências atuais, fazendo do texto memorialístico uma armadilha para quem o compõe: ao escrever sobre o passado, também se está escrevendo sobre o presente, ainda que de modo imperceptível. No caso específico dos textos autobiográficos, nos quais há uma instância narrativa de primeira pessoa a dirigir o relato que focaliza as experiências de um eu pretérito, a teia de tempos que a memória encena torna-se mais complexa. Unidos pelo mesmo pronome, o sujeito da escritura e o objeto de seu texto, feito personagem, são ao mesmo tempo dois e um só. Um, porque os personagens são, no fundo, a mesma pessoa empírica, conforme garante a assinatura firmada ao fim do relato; e são dois na medida em que a distância temporal que separa a ambos os torna distintos, sujeitos da vivência particular de seu tempo.

Na autobiografia Infância, de Graciliano Ramos (1945), o autor demonstra ter consciência da bipartição de seu texto - condição de todo relato memorialístico. 
Narrando os seus onze primeiros anos de vida encontramos um eu que em tudo se diferencia da figura que é descrita ao longo dos trinta e nove capítulos do volume. Enquanto o narrador se coloca no tempo do enunciado, vendo a si mesmo, no passado, como um caractere literário, o protagonista das ações evocadas, um menino frágil e tímido, primeiro filho de família numerosa, está circunscrito ao tempo da enunciação. Mais do que simplesmente distantes no tempo, ambos, narrador e personagem, embora sendo uma só pessoa, apresentam diferentes formas de observar, apreender e julgar a realidade, constituindo cada um, voz única e inconfundível. Marcados pelas questões que o momento em que se inseriam colocava, os dois eus de Infância desenham juntos um texto ambíguo, onde passado e presente se aproximam, ora afastando-se, ora confundindo-se até a indeterminação.

A natureza dupla da narrativa, expressa, no plano da pura enunciação, pela existência de dois olhares distintos a se lançarem sobre o passado de seu autornarradorprotagonista, também se faz notar no plano da significação da obra. Infância é, a um só tempo, obra dura e terna: ela tanto pode ser lida como uma impiedosa denúncia da "bárbara educação nordestina”, ${ }^{1}$ conforme assevera o próprio Graciliano Ramos, quanto pode ser tomada como um esforço de elaboração de um autorretrato ético que busca, em meio ao resgate do vivido, compreender e solidarizar-se com as personagens que no passado conviveram com o menino e o maltrataram. A alternância de tempos e sentidos, enfim, é a marca estrutural da obra e se faz visível em praticamente todos os níveis do texto. Este talvez seja o mais importante deles: identificado ao olhar da criança, personagem das memórias, o relato de Infância é sombrio, pessimista, muitas vezes resvalando no expressionismo ao retratar os castigos físicos e as angústias sofridas pelo menino-protagonista; em outros momentos, no entanto, quando o olhar predominante é o do adulto-escritor, as cores ficam menos carregadas, a vontade de entender as motivações alheias é maior e a matéria narrada se transforma, iluminada.

A caracterização de uma personagem importante do livro, a mãe do escritor, dá bem a medida da discrepância entre os olhares que se delineiam em Infância e do valor que essa diferença tem para o analista atento aos movimentos sutis do texto. Para o menino-personagem ela é "uma senhora enfezada, agressiva, ranzinza, sempre a mexerse (...), boca má, olhos maus que em momentos de cólera se inflamavam com um brilho

\footnotetext{
${ }^{1}$ RAMOS. Memórias do cárcere, p. 169.
} 
de loucura"; ${ }^{2}$ já segundo o adulto-escritor, as arestas da mãe mal-disposta tinham motivo e poderiam ter sido diferentes. Ele não só a condena ou vê de modo negativo; independentemente da validade dos argumentos apresentados em favor da personagem, o que retemos é o desejo de vê-la de outro modo, compreendê-la: “Se não existisse aquele pecado, tenho certeza de que minha mãe teria sido mais humana. (...) [ela] maltratava-se maltratando-nos.” 3

Ao referir-se à Mocinha, o "pecado”, filha avulsa do pai e uma das possíveis causas dos desgostos da mãe, o narrador procura expor um outro lado dessa personagem, observando-a sob uma perspectiva distinta daquela que ele mesmo, quando criança e protagonista de sua própria narrativa, foi capaz de adotar. E é assim com quase todos os demais retratados no livro: o pai, os vizinhos, professores e demais membros das pequenas comunidades em que o narrador viveu, todos mereceram um seu novo olhar. Sobre o Padre João Inácio, vigário apresentado no tempo do enunciado como homem de aparência assustadora e palavras rudes para com os paroquianos, o narradoradulto afirma, remetendo-nos ao momento da composição do texto: "Padre João Inácio não sabia (...) sorrir, brincar - e as nossas almas se fecharam para ele. Em Padre João Inácio, homem de ações admiráveis, só percebíamos dureza.” ${ }^{4}$ A demarcação de outro tempo é a mesma feita em relação à mãe do escritor. A forma verbal escolhida, “percebíamos”, deixa clara a intenção do embate entre o antigo modo de encarar a personagem e o juízo atual que se tem dela. A mãe, o pai, os professores, o vigário João Inácio e até o temido Fernando, assassino local e deflorador de moças pobres, todos personagens da obra, serão protagonistas de atitudes contraditórias, dando margem a inúmeras considerações de ordem ética e moral que o narrador vai inscrevendo no corpo do texto. Talvez o capítulo "Fernando" seja o melhor exemplo disso. O personagem homônimo, descrito como "bicho perigoso", 5 protegido do chefe político local, “dono de corpos e de almas", ${ }^{6}$ é praticante inveterado de injustiças de toda sorte. Fernando é segundo o ponto de vista infantil que o narrador assume - comparável aos piores criminosos da história; é “uma das recordações mais desagradáveis que ficaram”.7

\footnotetext{
${ }^{2}$ RAMOS. Infância, p. 16.

${ }^{3}$ RAMOS. Infância, p. 26.

${ }^{4}$ RAMOS. Infância, p. 71.

${ }^{5}$ RAMOS. Infância, p. 225.

${ }^{6}$ RAMOS. Infância, p. 223.

${ }^{7}$ RAMOS. Infância, p. 223.
} 
Acontece que, para surpresa daquele que rememora, uma atitude daquela singular criatura desestabiliza todo julgamento anteriormente feito: "um dia minha convicção se abalou profundamente". ${ }^{8}$ Numa tarde qualquer, ao ver pregos afiados soltos no chão, Fernando se preocupa com a segurança das crianças, entortando - num gesto inesperado -, os pedaços de metal que poderiam machucar os meninos que por ali andavam descalços. Tendo assistido a isso, comenta o narrador: "Então Fernando não era mau? Pensei num milagre. Julguei ter sido injusto. Fernando, o monstro, semelhante a Nero, receava que as crianças ferissem os pés."9

Assumindo tal postura contrastiva em relação ao passado, Graciliano Ramos evidencia sua condição presente, demonstrando ter plena consciência de que ao escrever suas memórias ele não só expõe fatos esquecidos, mas também se inscreve no texto com todos os seus valores e contradições atuais. Com esse mesmo gesto o autor afirma também o caráter ficcional e móvel de suas lembranças, pois as apresenta segundo diferentes miradas, enfatizando sua relatividade. Esse conjunto de características observadas até aqui no texto do autor permitem-nos afirmar, retomando algumas considerações feitas acima sobre a natureza da obra memorialística, que o jogo presente/passado que se coloca em Infância apresenta-se como reflexão. A grande vocação da obra parece ser a de refletir sobre o passado a partir de um ponto de vista presente, ao invés de contentar-se com o fácil resgate de vivências perdidas e sua descrição, como é comum em certa tradição memorialística brasileira. Conforme afirma o crítico Wander Melo Miranda, o passado, na obra de Graciliano Ramos, "é eleito como um lugar de reflexão - no sentido simultâneo de retratar e reflexionar”. ${ }^{10}$

Refletir sobre um fenômeno humano qualquer é tentar compreendê-lo; investigar as suas origens, conhecer as circunstâncias específicas que o envolveram, entender as possíveis razões de seus atos e de suas singularidades. Refletir, compreender: ações vizinhas que visam aproximar o ser pensante das pessoas e coisas que o cercam. Aproximação que se realiza pela razão, mas que inclui também o afeto, uma vez que aproximar-se (ou re-aproximar-se) sugere contato, sensação. Nas memórias de Graciliano Ramos esse parece ser o sentido apropriado do verbo refletir: mais do que analisar ou decompor friamente um episódio lembrado, a prática reflexiva que se

\footnotetext{
${ }^{8}$ RAMOS. Infância, p. 227.

${ }^{9}$ RAMOS. Infância, p. 227.

${ }^{10}$ MIRANDA. Graciliano Ramos, p. 161.
} 
processa em Infância aponta para o desejo de compreender o outro, penetrar-lhe as motivações íntimas, entender suas ações sem julgá-las apressadamente, mesmo quando se trata de recordar humilhações sofridas ou pancadas injustamente recebidas.

Impressiona em Infância a narrativa dos sofrimentos do menino-personagem. A brutalidade dos pais e professores contra a criança é assustadora: surras, chateações, desprezo são constantes. O leitor acompanha, atônito, o infeliz destino do infante: "Medo. Foi o medo que me orientou nos primeiros anos, pavor." ${ }^{11}$ É exatamente por ser obra plena de angústia, na qual várias personagens aparecem grotescamente deformadas por um olhar infantil que age o tempo todo guiado pelo medo e pela dor, que o desejo de compreensão do passado manifesto pelo narrador-adulto avulta em seu contraste e emociona. Referindo-se ao pai, homem turvo, explosivo, de “cara enferrujada” ${ }^{12}$ e "fala tremenda", ${ }^{13}$ capaz de chicotear o filho por causa de um cinturão perdido, o narrador vai afirmar: "Hoje acho naturais as violências que o cegavam", ${ }^{14}$ numa tentativa de racionalizar o comportamento bestial do Outro em busca de suas razões prováveis.

Em meio a um relato doloroso, que no tempo do enunciado apresenta o mundo como um inferno cheio de punições e incongruências, a voz narrativa que se ergue no tempo da enunciação e procura, sem esquecer ou minimizar a experiência sofrida, redimensionar essa experiência e até mesmo justificá-la em certo grau, se apresenta como resultado de enorme esforço ético do autor que vemos se processar enquanto o texto vai se escrevendo. Parece que o valor da palavra escrita, da vida reinventada como texto na obra de Graciliano Ramos, só se justifica pela possibilidade de questionar a si mesmo e aos seus juízos estabelecidos. Assim como lembrar, para o autor, é sempre refletir, o exercício da escrita para ele não é só ato estético - passa também pelo crivo rigoroso de um programa ético.

Os termos da equação relacionada a esse processo também se ampliam, alargando seu horizonte de significação. Lembrança e esquecimento, binômio-chave da operação memorialística realizada em Infância, passam a equivaler, segundo queremos propor, ao par conceitual ressentimento e compreensão: nos trechos do livro em que prevalece o primeiro desses termos (a lembrança), o texto tinge-se com as cores do

\footnotetext{
${ }^{11}$ RAMOS. Infância, p. 16.

${ }^{12}$ RAMOS. Infância, p. 35.

${ }^{13}$ RAMOS. Infância, p. 16.

${ }^{14}$ RAMOS. Infância, p. 36.
} 
ressentimento, e apresenta de modo excessivamente negativo, e carregado, os personagens e as situações em foco. Majoritariamente, esses trechos são narrados a partir do ponto de vista da criança, protagonista das ações que transcorrem no tempo do enunciado.

Agora, nos trechos em que prevalece o esquecimento - os momentos decisivos do livro - a compreensão do Outro se afirma como postura ética e estratégia narrativa principal, o que faz com que a atitude do memorialista passe a ser a de humanizar os personagens retratados em vez de apenas condená-los, e isso sem que o autor abra mão do olhar crítico que caracteriza sua visão de mundo, dado que a prática do esquecimento, em Infância, não pode ser confundida com inclinação à indulgência ou ao sentimentalismo.

Se a incerteza e a nebulosidade são as características que, é possível afirmar, definem o olhar do personagem-narrador em Infância (aquele que se identifica ao ponto de vista da criança), pode-se dizer, por outro lado, que a busca por clareza e compreensão da experiência vivida é o elemento que melhor caracteriza o ponto de vista do adulto-narrador (aquele se identifica com o memorialista). Para ele, narrar é tentar imprimir sentido ao que ficou para trás, mesmo que o passado se apresente em retalhos soltos, apenas "rasgões num tecido negro". ${ }^{15}$ Os percalços de sua formação como indivíduo, a descoberta das suas aptidões, o contato e o confronto com o Outro, tudo isso só interessa a esse narrador - que se sabe distante no tempo e no espaço dos acontecimentos que relata - como matéria de reflexão. Repetir cenas já vistas, recuperar pessoas apagadas, recompor (ou inventar) diálogos obliterados pelo tempo parece não bastar como atividade fechada sobre si mesma. A simples evocação dá lugar aqui a uma prática distinta: o ato de recordar se une ao de analisar, formando ambos um só gesto, uma ação contínua.

Por fim, partindo das premissas e análises levantadas acima e identificando na extensa fortuna crítica de Infância a ausência de trabalhos que se dedicaram a observar o debate ético que tem lugar na obra, é possível afirmar que, predomina no primeiro livro de memórias de Graciliano Ramos sentimento muito diverso daquele frio pessimismo comumente atribuído a ele. Ao contrário do que se costuma pensar, a compreensão do Outro (assumida como uma espécie de dever moral pelo autornarrador-personagem) constitui-se como elemento-chave de uma visão de mundo mais

\footnotetext{
${ }^{15}$ RAMOS. Infância, p. 11.
} 
aberta e positiva - próxima mesmo do humanismo - que se delineia na obra. Verdadeiro exercício autocrítico, a escrita memorialística de Infância é, a um só tempo, exemplo da exata junção entre ética e estética promovida pela/ na obra de Graciliano Ramos, como também se revela uma reflexão inovadora e radical sobre o gênero autobiográfico, tantas vezes imerso em práticas narcísicas e pobremente reconfortantes para o sujeito da escrita.

\section{ABSTRACT}

This work presents an interpretation of Graciliano Ramos's book of childhood memoirs: Infância. It has as its major theme the ethical debate, which is recurrent throughout the whole book. Considered as having a pessimistic and disillusioned outlook by the critics, Infância was read almost exclusively with a focus on the same issues throughout time: fear, violence, resentment. Taking a contrary stance, I tried to show in this paper that a less negative view of men and of the world prevails in this book.

KEYWORDS

Autobiography, resentment, ethic

\section{REFERÊNCIAS}

CARPEAUX, Otto M. Visão de Graciliano. In: . Ensaios reunidos. Rio de Janeiro: Topbooks, 1999. p. 443-449.

FREUD, Sigmund. A psicopatologia da vida quotidiana. Trad. Klaus Scheel. Rio de Janeiro: Imago, 1987.

GINZBURG, Jaime. Infância e violência. Expressão - Revista do Centro de Artes e Letras. Santa Maria: UFSM, p. 129-132, jan./jun. 2000.

KARPA-WILSON, Sabrina. The ethical self in Graciliano Ramos's Infância. LuzoBrazilian Review, Madison - University of Wisconsin, n. 42, p. 154-178, 2005. Disoponível em: <http://www.lbr.uwpress.org>. Acesso em: 20 dez. 2007.

KEHL, Maria Rita. Ressentimento. São Paulo: Casa do Psicólogo, 2004.

LEITÃO, Cláudio C. Líquido e incerto: memória e exílio em Graciliano Ramos. Niteroi: Ed. UFF, 2003.

LEJEUNE, Philippe. Le pacte autobiographique. Paris: Seuil, 1996.

MIRANDA, Wander Melo. Corpos escritos. Belo Horizonte: Ed. UFMG; São Paulo: Edusp, 1992. 
MIRANDA, Wander Melo. Graciliano Ramos. São Paulo: Ed. Publifolha, 2004.

NAXARA, Márcia; CAPELARI, Regina. Memória e (res)sentimento: indagações sobre uma questão sensível. Campinas: Editora Unicamp, 2004.

RAMOS, Graciliano. Infância. São Paulo: Record, 2003.

RAMOS, Graciliano. Memórias do Cárcere. São Paulo: Record, 1993. 2. v. 